\title{
Desastres, desigualdades, violências e processos de democratização
}

\author{
Disasters, inequalities, violence and democratization processes \\ Desastres, desigualdades, violencia y procesos de democratización
}

Jose Esteban Castro ${ }^{1}$

\section{Resumo}

CASTRO, J. E. Desastres, desigualdades, violências e processos de democratização. Rev. C\&Trópico, v. 45, n. 2, p. 135-157 2021. DOI: https://doi.org/10.33148/cetropi$\operatorname{cov} 45 \mathrm{n} 2(2021) \operatorname{art} 8$

O artigo discute o significado da violência no surgimento, manutenção e erosão das ordens socioecológicas. Ele se concentra na interconexão entre a violência contra comunidades marginalizadas, afetadas pela rápida expansão de formas frequentemente criminosas de acumulação primitiva promovidas ou implementadas diretamente por governos e atores privados multinacionais, muitas vezes com o apoio tácito ou explícito de instituições internacionais cujo mandato original foi preservar a paz e promover o desenvolvimento universal. Ainda apresenta evidências do impacto global de conflitos e violência relacionados ao meio ambiente, complementados com exemplos empíricos da América Latina, relacionados à expansão das atividades extrativistas e aos impactos desigualmente distribuídos de eventos extremos geofísicos ou climáticos, entre outros, que continuam a induzir formas amplas e múltiplas de resistência social. O autor enfatiza a produção de desigualdade e injustiça estruturais por meio da violência organizada sistematicamente e da criminalização de atores sociais que visam a defender seus territórios, meios de subsistência e direitos básicos. $\mathrm{O}$ argumento destaca a contradição fundamental entre o compromisso discursivo com os princípios e processos democráticos por parte de governos e instituições internacionais e as ilegalidades e atrocidades violentas cometidas nos territórios contra comunidades indefesas. Discute os desafios enfrentados pelos cientistas sociais para produzir entendimentos e explicações mais avançadas e complexas desses processos, que possam contribuir para a construção de ordens socioecológicas mais humanas.

Palavras-chave: Violências socioecológicas. Ordens socioecológicas. Processos de democratização. Desigualdade estrutural e injustiça. América Latina.

1 Graduado e Professor em Sociologia pela Universidade de Buenos Aires (1983-1988), Mestre em Ciências Sociais pela Faculdade Latino-Americana de Ciências Sociais (FLACSO), Sede do México (19901992) e Doutor em Ciência Política pela Universidade de Oxford (1993-1998). Ele coordena a rede internacional de pesquisa WATERLAT-GOBACIT (http://www.waterlat.org), dedicada à pesquisa, ensino e ação prática em relação à política e gestão da água. E-mail: jecastro.conicet@gmail.com; Orcid: https:// orcid.org/0000-0001-6106-4313 


\section{Abstract}

CASTRO, J. E. Disasters, inequalities, violence and democratization processes. Rev. C\&Trópico, v. 45, n. 2, p. 135-157, 2021. DOI: https://doi.org/10.33148/cetropicov45n2(2021)art8

The article discusses the significance of violence in the emergence, maintenance, and erosion of socio-ecological orders. It focuses on the interconnection between violence against marginalized communities affected by the rapid expansion of often criminal forms of primitive accumulation promoted or directly implemented by governments and multinational private actors, often with the tacit or explicit support from international institutions whose original mandate has been to preserve peace and promote universal development. It still presents evidence of the global impact of environment-related conflict and violence, complemented with empirical examples from Latin America, related to the expansion of extractivist activities and the unequally distributed impacts of extreme geophysical or weather-related events, among other, which continue to prompt widespread and multiple forms of social resistance. The author emphasizes the production of structural inequality and injustice through systematically organized violence and criminalization of social actors who aim to defend their territories, livelihoods, and basic rights. The argument highlights the fundamental contradiction between the discursive commitment to democratic principles and processes by governments and international institutions, and the illegalities and violent atrocities committed on the ground against defenseless communities. It discusses the challenges faced by social scientists to produce more advanced and complex understandings and explanations of these processes that may contribute towards the construction of more humane socio-ecological orders.

Keywords: Socio-ecological violences. Socio-ecological orders. Democratization processes. Structural inequality and injustice. Latin America.

\section{Resumen}

CASTRO, J. E. Desastres, desigualdades, violencia y procesos de democratización.

Rev. C\&Trópico, v. 45, n. 2, p. 135-157, 2021. DOI: https://doi.org/10.33148/cetropi$\operatorname{cov} 45 \mathrm{n} 2(2021) \operatorname{art} 8$

El artículo analiza la importancia de la violencia en el surgimiento, mantenimiento y erosión de los órdenes socioecológicos. Se centra en la interconexión entre la violencia contra las comunidades marginadas afectadas por la rápida expansión de formas a menudo criminales de acumulación primitiva promovidas o implementadas directamente por gobiernos y actores privados multinacionales, a menudo con el apoyo tácito o explícito de instituciones internacionales cuyo mandato original ha sido preservar paz y promover el desarrollo universal. Presenta evidencia del impacto global de los conflictos y la violencia relacionados con el medio ambiente, complementados con ejemplos empíricos de América Latina, relacionados con la expansión de las actividades extractivistas y los impactos distribuidos de manera 
desigual de eventos extremos geofísicos o climáticos, entre otros, que continúan para suscitar formas múltiples y generalizadas de resistencia social. El autor hace énfasis en la producción de desigualdad e injusticia estructural a través de la violencia sistemáticamente organizada y la criminalización de los actores sociales que buscan defender sus territorios, medios de vida y derechos básicos. El argumento destaca la contradicción fundamental entre el compromiso discursivo con los principios y procesos democráticos por parte de gobiernos e instituciones internacionales, y las ilegalidades y atrocidades violentas cometidas en el terreno contra comunidades indefensas. Se analizan los desafíos que enfrentan los cientificos sociales para producir entendimientos y explicaciones más avanzados y complejos de estos procesos que pueden contribuir a la construcción de órdenes socioecológicos más humanos.

Palabras clave: Violencias socioecológicas. Órdenes socioecológicos. Procesos de democratización. Desigualdad e injusticia estructural. America Latina.

\section{Introdução}

Em 24 de fevereiro de 2019, Francisco Lopez, um líder de 28 anos da comunidade indígena Ava Guarani Tacuara’i, foi assassinado em frente ao Congresso Nacional do Paraguai na capital Assunção. Ele representava a luta de famílias camponesas que foram expulsas violentamente de suas terras em outubro de 2018 por forças paramilitares agindo em nome de poderosos interesses ligados à expansão das atividades extrativistas no interior do país (ACI, 2019). O evento tem um simbolismo poderoso que lembra a relação turbulenta entre as instituições formais da democracia ocidental e os processos reais de democratização, particularmente, mas não apenas nas periferias da atual ordem mundial. Uso este exemplo do Paraguai não para buscar qualquer reivindicação de originalidade ou porque adiciona qualquer nova evidência empírica excepcional a um debate acadêmico e político de longa data. Longe disso, em grande escala, deslocamento de populações e violência criminal exercida contra comunidades locais, principalmente, mas não apenas, indígenas e afrodescendentes, têm sido moeda comum nos países formalmente democráticos do continente americano e em outros lugares. No entanto, trazer este caso à luz ajuda a tornar observáveis as lutas sociais contra a violência do silêncio e da invisibilização que afetam populações humanas marginalizadas em regiões muito esquecidas como o Paraguai, que é um dos territórios afetados por uma expansão agressiva de estratégias de acumulação primitivas promovidas principalmente por governos, organizações internacionais e corporações transnacionais (ORTEGA, 2013; ARECO; PALAU, 2016).

Nesse sentido, este artigo discute a relação entre violência e mudança social enfocando processos pertencentes, em linhas gerais, à dimensão socioecológica. As lutas sociais ligadas a diferentes formas de violência socioecológica têm uma longa história. Isso vai desde lutas contra os impactos da poluição do solo, do ar ou da água 
ao bem-estar humano, contra os deslocamentos em massa de populações para construir obras de infraestrutura ou contra a apropriação da terra, da água e de outros bens naturais, incluindo a própria vida (ou seja, através da biopirataria, mercantilização do corpo humano, ou táticas semelhantes) por poderosos atores privados e corporativos, entre outros. No entanto, nas últimas décadas, essas formas de violência foram exacerbadas, entre outras razões, por causa da implacável expansão global da mercantilização capitalista e dos processos e mecanismos relacionados, que continuam a suscitar formas generalizadas e múltiplas de resistência social. O objetivo é discutir, a partir de uma abordagem política ecológica de base sociológica, a interação entre violências e resistências socioecológicas como forças estruturantes, impulsionadoras da destruição, da transformação ou do surgimento de ordens socioecológicas. Meu principal interesse diz respeito às formas de violência que afetam as comunidades locais e outros atores que por diferentes motivos estão na vanguarda das lutas sociais ligadas à defesa das condições básicas de vida, como é o caso das lutas contra os impactos negativos de atividades extrativistas mal reguladas, não regulamentadas e muitas vezes ilegais, a mercantilização e privatização de bens comuns e públicos ou de impactos desigualmente distribuídos de eventos geofísicos extremos ou relacionados ao clima, entre outros processos. As reflexões fundamentam-se em pesquisas desenvolvidas no âmbito de um projeto em andamento que busca a relação entre desigualdades e injustiças socioecológicas e processos de democratização (DESDEMO, 2019). Embora o projeto trate de exemplos da América Latina, a discussão tem uma relevância mais ampla dada a abrangência global do problema. A primeira parte discute brevemente o conceito de violência e seu papel nos processos sociais. A segunda parte explora a guerra e o conflito como formas específicas de violência e sua relação com os processos socioecológicos, incluindo uma discussão de exemplos empíricos. Na terceira parte, examino exemplos de como, apesar do acúmulo de conhecimento e de evidências crescentes em contrário, há uma abordagem persistente que minimiza, quando não nega totalmente, o papel dos fatores antropogênicos em processos e eventos ambientais extremos, incluídos os desastres. As conclusões sintetizam os principais argumentos e destacam alguns dos desafios que enfrentamos em relação à produção de conhecimento sobre as ordens socioecológicas e sua relação com os processos de democratização.

\section{Violência e processos sociais}

Embora a teorização sistemática da violência possa provavelmente remontar ao século XVI (JOAS; KNÖAS; KNÖBL, 2013), o pensamento social sobre, e mais importante, a regulação das relações sociais violentas é tão antigo quanto a história humana registrada. Assim, o que Johan Galtung definiu há muito tempo como um "conceito ampliado de violência" (GALTUNG, 1969, p. 168) inclui formas de violência que inspiraram as primeiras leis desenvolvidas por humanos. Por exemplo, as antigas sociedades do Oriente Médio consagraram o princípio de que a água para consumo humano e animal essencial não podia ser negada a ninguém, um princípio conhecido como 
“Direito à Sede" (CAPONERA, 1954; HIRSCH 1959, CIVIC, 1998). Claramente, a necessidade de introduzir legislação sobre o assunto foi levantada pela ocorrência frequente do que Galtung chamou de "violência somática pessoal", que incluiria ações prejudiciais como envenenamento por água e negação de ar, água e comida (GALTUNG 1969: 174). Essa forma de violência, é claro, não foi erradicada, embora regulamentações e legislações relevantes tenham existido por milênios, como tem mostrado a sua persistência entre as sofisticadas sociedades humanas do século XXI. Um exemplo recente é o que Paul Mohai chamou de "o exemplo mais flagrante de injustiça ambiental", referindo-se à série de decisões conscientes do governo municipal de Flint, Michigan, nos Estados Unidos, levando ao "envenenamento da água da cidade" (MOHAIi, 2018). Não apenas governos e outros detentores de poder em sociedades nominalmente civilizadas tendem a "naturalizar" e justificar a negação desses bens essenciais a setores da população, normalmente os mais pobres e socialmente marginalizados, mas também recorrem à criminalização das atividades daqueles que ousam defender o "Direito à Sede", ou, por extensão, o "Direito à Fome", o "Direito a Dormir" ou mesmo o "Direito a Respirar" (FERNANDEZ EVANGELISTA; JONES, 2013; ANDREWS, 2017; FAO, 2019; NATIONAL COALITION FOR THE HOMELESS, 2019).

A busca pelo desenvolvimento de um "conceito ampliado de violência", como sugerido por Galtung décadas atrás, tem o objetivo de ir além da definição convencional de violência como o uso da força física para causar ferimentos, danos ou destruição. Uma amostra da literatura especializada mostra uma ampla gama de termos e formas de apropriação do conceito que trazem à tona aspectos multidimensionais e multiescalares da violência para além da noção convencional (Quadro 1).

Quadro 1: Conceituação estendida e adjetivação de "violência

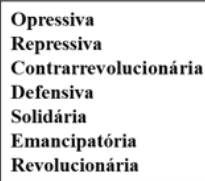

\begin{tabular}{|l|}
\hline Legitima \\
Legal \\
Ilegítima \\
Ilegal \\
Criminal \\
\hline
\end{tabular}

\begin{tabular}{|l|}
\hline Pública \\
estatal \\
Militar \\
Corporativa \\
No espaço de \\
trabalho \\
Privada \\
Doméstica \\
Interpessoal \\
Autoinfligida \\
\hline
\end{tabular}

Monopólica Competitiva mercadorizada Tecnológica Industrializada

\begin{tabular}{|l|}
\hline Direta \\
Intencional \\
Organizada \\
Institucional \\
Estrutural \\
Latente \\
Indireta \\
Não intencional \\
voluntária \\
aleatória \\
\hline
\end{tabular}

\begin{tabular}{|l|}
\hline De massa \\
De Classe \\
Tribal \\
Racial \\
De Gênero \\
intergeneracional
\end{tabular}

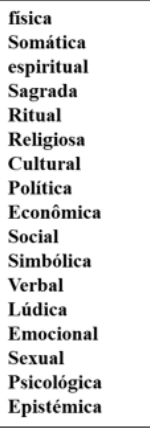

Natural

Da natureza

Ecológica

Socioecológica

ambiental 
Agrupei os termos para refletir alguns atributos comuns, incluindo alguns especificamente relacionados com o tópico do artigo, como violências "naturais", "da natureza" ou "ambientais", que consideraremos mais tarde com mais detalhes. A maioria dos termos na Figura 1 estão interligados e conectados a conceitos intimamente relacionados, como, por exemplo, em "violência lenta, necropolítica e poluição petroquímica" (DAVIES, 2018), "violência militar ambiental e paisagens armadas" (HALL, 2017, p. 4), "Violência judicializada" (ARECO, PALAU, 2016) ou "Violência ambiental e genocídio" (ZIMMERER, 1914). A ampla gama de termos, adjetivos e suas interconexões mútuas ilustram a centralidade da violência, em suas múltiplas formas e escalas, no desenvolvimento de processos, ordens e desordens sociais.

$\mathrm{O}$ fato de a violência ser um fator estruturante dos processos sociais foi uma preocupação central para Norbert Elias e um componente crucial de sua teorização sobre o "processo civilizador" (ELIAS, 1994). Baseando-se em Max Weber, deu centralidade ao que chamou de "mecanismo de monopólio", isto é, um processo histórico-social cego e não planejado que ao longo de vários séculos levou à transformação da ordem feudal na Europa e ao surgimento de uma nova ordem social estruturada em torno dos estados-nação. O mecanismo de monopólio referia-se particularmente ao que Weber denominou de "monopólio do uso legítimo da força física dentro de um determinado território”, característico do Estado-nação, e incluía não só o monopólio dos meios de violência, mas também dos poderes de taxação (WEBER, 1978, p. 909; MENNELL, 1992, p. 66-79; ELIAS, 1994, p. 338-355). A recepção da teoria de Elias foi morna, principalmente no que diz respeito à relação entre violência e o "processo civilizador" e sua aplicabilidade a sociedades fora do pequeno grupo que forneceu a principal evidência empírica para seu estudo, a saber, França, Alemanha e Grã-Bretanha (GOUDSBLOM, 1994; FLETCHER, 1997; LINKLATER; MENNELL, 2010; PEPPERELL, 2016; LANDINI; DEPELTEAU, 2017). No entanto, o trabalho de Elias fornece pistas importantes para o estudo do papel da violência na dinâmica das configurações sociais em constante mudança, incluindo o surgimento e a transformação das ordens sociais. Elaborando o trabalho de Elias, o sociólogo holandês Johan Goudsblom cunhou o que chamou de "o paradoxo da pacificação", a tensão permanente entre "paz" e "guerra", destacando que a pacificação é frequentemente alcançada por meio de muita violência, e que a pacificação interna dos territórios através da monopolização dos meios de violência é uma condição prévia para o exercício efetivo da violência interestatal “organizada”, particularmente as guerras (GOUDSBLOM, 2001).

Nesse sentido, pelo menos historicamente e em termos da escala de destruição envolvida, e talvez, apesar de seu caráter mutável, a guerra continua a ser a manifestação mais extrema de violência, definida como o uso de força física extrema. E ainda, como Carl von Clausewitz colocou, pelo menos "em teoria", "a guerra é um ato de violência destinado a forçar o inimigo a fazer nossa vontade" (CLAUSEWITZ, 1989, p. 90). Ele também argumentou 
Se as guerras entre nações civilizadas são muito menos cruéis e destrutivas do que as guerras entre selvagens, a razão reside nas condições sociais dos próprios Estados e em suas relações uns com os outros. Essas são as forças que dão origem à guerra; as mesmas forças a circunscrevem e moderam (CLAUSEWITZ, 1989, p. 90).

A análise de Clausewitz forneceu uma explicação estrutural e sistêmica da guerra e insistiu que o uso da violência na guerra era um meio de forçar o inimigo a aceitar nossa vontade, que o objetivo não era obliterar o inimigo. Mesmo que, na prática, a dinâmica da guerra muitas vezes leve a extremos no uso da violência, ele argumentou que este não era um objetivo principal e que as "condições sociais" e as relações entre as nações "civilizadas” eram fatores-chave na prevenção dessas situações extremas. De uma forma não muito diferente de certos aspectos da abordagem de Elias, Clausewitz baseou suas reflexões na experiência da guerra entre os países europeus "civilizados", particularmente durante o período napoleônico. No entanto, a partir de meados do século XIX, a violência militar e a própria guerra foram radicalmente transformadas. Como Eric Hobsbawm argumentou em uma palestra sobre o que ele chamou de "barbárie", realizada no rescaldo da Guerra do Golfo Pérsico (1990-1991), as nações civilizadas têm experimentado uma séria regressão das condições sociais e convenções morais que historicamente ajudaram a circunscrever e moderar os impactos da guerra. Nas palavras de Hobsbawm:

Entendo "barbárie" significando duas coisas. Primeiro, a ruptura e o colapso dos sistemas de regras e comportamento moral pelos quais todas as sociedades regulam as relações entre seus membros e, em menor grau, entre seus membros e os de outras sociedades. Em segundo lugar, quero dizer, mais especificamente, a reversão do que podemos chamar de projeto do Iluminismo do século XVIII, ou seja, o estabelecimento de um sistema universal de tais regras e padrões de comportamento moral, consubstanciados nas instituições dos Estados dedicados ao racional progresso da humanidade: à vida, à busca da felicidade, à igualdade, à liberdade e à fraternidade ou o que seja. Ambas estão ocorrendo agora e reforçam os efeitos negativos uma da outra em nossas vidas (HOBSBAWM, 1994, p. 45).

Hobsbawm observou com veemência que Clausewitz pressupunha que as regras de guerra aceitas pelos países civilizados incluíam o respeito à vida dos prisioneiros de guerra e das populações civis, algo que os rebeldes e os revolucionários também seguiam, mas que essas regras de comportamento moral não podem mais ser consideradas em funcionamento, como mostrado pelo comportamento incivilizado e criminoso que caracteriza as guerras contemporâneas. Compreendo que citar a poderosa 
defesa de Hobsbawm do Iluminismo, das instituições dos estados nacionais e da ideia de "progresso racional" pode não apenas levantar algumas sobrancelhas, mas também provocar divergências entre muitos dos envolvidos nas lutas contra a desigualdade e injustiça socioecológica no mundo todo. Isso parece compreensível, dado o papel proeminente desempenhado pelos estados-nação na "traição" da promessa de desenvolvimento e progresso universais (NOORGARD, 1994; MERCHANT, 2006). No entanto, a traição da civilização pelas próprias instituições que deveriam defender seus princípios e assegurar seu avanço é uma característica essencial da barbárie denunciada por Hobsbawm. Eu volto a esta discussão mais adiante.

\section{Guerra, conflitos e violências socioecológicas}

A referência à guerra nos parágrafos anteriores não existe apenas por seu significado em uma discussão conceitual de "violência", mas porque tem implicações diretas para a consideração das interligações entre violências socioecológicas e ordens sociais, como os exemplos a seguir ilustram. Em agosto de 1995, o então vice-presidente de Desenvolvimento Ambientalmente Sustentável do Banco Mundial, Ismail Serageldin, declarou que, embora muitas guerras do século XX fossem por causa do petróleo, no século XXI as guerras seriam por causa da água (CROSETTE, 1995). Esta foi uma afirmação importante, mas não uma ideia original, já que a noção de guerras ligadas aos recursos naturais e ao meio ambiente de forma mais geral, entre as quais as "guerras da água" se destacavam, estava se tornando parte da agenda da "segurança internacional” (GLEICK, 1993). Em junho de 1999, o Programa das Nações Unidas para o Meio Ambiente (PNUMA) publicou um relatório especial sobre as ligações entre meio ambiente e conflito, incluindo guerras (SCHWARTZ; SINGH, 1999). No prefácio do relatório, o então Diretor Executivo do Pnuma, Klaus Toepfer, afirmou que "é claro que a oportunidade para a humanidade combater o conflito internacional e intranacional deve ser vista à luz das conexões entre as condições de recursos ambientais e o conflito". Os comentários de Toepfer foram amplamente divulgados pela mídia global. No ano 2000, o Conselho Nacional de Inteligência dos Estados Unidos anunciou que no período de 2000-2015 “as prioridades externas dos EUA seriam mais transnacionais" para lidar com problemas crescentes, incluindo "competição por recursos naturais escassos, como água [...] e crises ambientais” (NIC 2000, p. 18). Em 2002, um grupo de organizações preocupadas com a conservação dos recursos naturais publicou um relatório intitulado "Conservando a Paz: Recursos, Meios de Vida e Segurança”, argumentando que as fontes tradicionais de conflito humano eram exacerbadas por problemas ambientais, que "colocavam uma pressão massiva sobre sociedades e especialmente para seus membros mais pobres", e que a gestão melhorada e a conservação planejada dos recursos naturais e da biodiversidade poderiam" contribuir para a paz e a estabilidade "e, por extensão, para o "desenvolvimento e justiça social" (MATTHEW et al. 2002, p. 4-5). Então, em fevereiro de 2006, o ex-secretário de Defesa britânico John Reid anunciou que as forças armadas do país seriam colocadas de prontidão para intervir em 
qualquer lugar do mundo para enfrentar a crescente ameaça de violência e conflito político relacionado com o aquecimento global e seu impacto sobre os recursos naturais, especialmente a água (RUSSELLL; MORRIS, 2006). Talvez muito menos proeminente na mídia internacional foi a decisão anunciada em abril de 2008 pelo governo dos Estados Unidos do presidente George W. Bush de restabelecer a $4^{\text {a }}$ Frota que patrulhava os mares do Caribe e da América Central e do Sul, que havia sido desativada em 1950 desde o fim do Mundo Segunda Guerra (Departamento da Marinha dos Estados Unidos da América, 2008). Esta decisão “provocou reações de indignação e raiva” na América Latina, e algumas semanas depois, quando os governos sul-americanos assinaram o Tratado Constitutivo da União de Nações Sul-Americanas (UNASUL) em 23 de maio de 2008, criaram um grupo de trabalho militar (DABÈNE. 2014, p. 85). Vários países da região, notoriamente Argentina, Brasil e Venezuela, redefiniram os objetivos de suas forças militares para se concentrar na defesa contra possíveis tentativas de potências estrangeiras de obter controle sobre seus recursos naturais, notoriamente petróleo e água (DE PAULA, 2009). Desenvolvimentos recentes na região sugerem que essas preocupações não foram exageradas, embora eu não possa desenvolver este tópico aqui por razões de espaço e foco.

Os exemplos apresentados no parágrafo anterior deixam pouco espaço para dúvidas sobre a forte relação entre conflito extremo e violência, potencial ou real, e processos e ordens socioecológicas (KULETZ, 2001; DOWNWY; BONDS, 2010; HSIANG et al. 2013, HALL, 2017). Além de seu próprio significado para a discussão, enfocar a guerra como a principal expressão de "violência extrema" fornece um sinalizador para a análise. No entanto, apesar de seus enormes impactos, as guerras e outros conflitos humanos de grande escala representam apenas uma pequena parcela das violências associadas às ordens socioecológicas. Como mostrado abaixo, embora até agora tenha havido poucas, ou nenhuma, guerras abertas, no sentido convencional, explicitamente declaradas pelo controle dos recursos naturais, violência generalizada e extrema contra as comunidades locais, principalmente, mas não apenas, indígenas e afro-descendentes, e as lutas sociais que se seguiram para defender territórios e meios de subsistência tornaram-se endêmicas na América Latina e em outras regiões.

Nesse contexto, consideremos o caso dos Deslocados Internos (IDP), que é acompanhado desde o ano de 2008 pelo Centro de Monitorização do Deslocamento Interno (IDCM). O IDCM produziu estimativas globais anuais de IDPs resultantes de "conflitos e violência" e "desastres", que incluem eventos geofísicos como terremotos e erupções vulcânicas e eventos "relacionados ao clima”, como tempestades, inundações, secas etc. Os números do IDCM devem ser lidos com cautela, não apenas pelo fato de serem estimativas, mas também porque "desastres" também podem ser a causa de conflito e violência e, portanto, a diferença entre as duas categorias pode ser um tanto confusa. Ainda assim, os resultados fornecem uma perspectiva muito útil da situação, conforme mostrado na Tabela 1, que apresenta informações do último relatório do IDCM coletado em mais de 140 países para o período 2008-2017. 
Tabela 1: Estimativas de Pessoas Internamente Deslocadas por conflito e violência ou desastres entre 2008 e 2017, em percentuais e números absolutos

\begin{tabular}{llll}
\hline Ano & Conflitos \& Violência & Desastres & Total \\
\hline 2008 & $11.19 \%$ & $88.81 \%$ & $100 \%$ \\
& $(4.6)$ & $(36.5)$ & $(41.1)$ \\
\hline 2009 & $28.02 \%$ & $71.98 \%$ & $100 \%$ \\
& $(6.5)$ & $(16.7)$ & $(23.2)$ \\
\hline 2010 & $6.4 \%$ & $93.6 \%$ & $100 \%$ \\
& $(2.9)$ & $(42.4)$ & $(45.3)$ \\
\hline 2011 & $18.92 \%$ & $81.08 \%$ & $100 \%$ \\
& $(3.5)$ & $(15)$ & $(18.5)$ \\
\hline 2013 & $16.92 \%$ & $83.08 \%$ & $100 \%$ \\
& $(6.6)$ & $(32.4)$ & $(39)$ \\
\hline 2014 & $27.06 \%$ & $72.94 \%$ & $100 \%$ \\
& $(8.2)$ & $(22.1)$ & $(30.3)$ \\
\hline 2015 & $36.54 \%$ & $63.46 \%$ & $100 \%$ \\
& $(11)$ & $(19.1)$ & 30.1 \\
\hline 2016 & $30.94 \%$ & $69.06 \%$ & $100 \%$ \\
& $(8.6)$ & $(19.2)$ & $(27.8)$ \\
\hline 2017 & $22.19 \%$ & $77.81 \%$ & $100 \%$ \\
& $(6.9)$ & $(24.2)$ & $(31.1)$ \\
\hline
\end{tabular}

Fonte: Elaborado pelo autor a partir de IDCM, 2018: 2.

A tabela 1 mostra que, embora o número de deslocados internos tenha diminuído em relação aos picos registrados em 2008 e 2010, com uma estimativa de 41,1 e 45,3 milhões de deslocados internos, respectivamente, para cada ano, o deslocamento populacional em grande escala tornou-se uma característica permanente em todo o mundo. Além disso, a cada ano, o número estimado de deslocados internos produzidos por "desastres" excedeu em muito os números resultantes de "conflito e violência", atingindo um pico em 2010, quando 93,6\% dos deslocados internos foram causados por desastres. A Tabela 2 complementa as informações de um ângulo diferente, focando nos tipos específicos de eventos incluídos sob o rótulo de "desastres", mostrando os números de deslocados internos registrados em 2017. 
Tabela 2: Estimativas de Deslocados Internos por desastres em 2017, em milhões de pessoas.

\begin{tabular}{lllllr}
\hline & \multicolumn{2}{c}{ Subtotal 1 } & Subtotal 2 & Total \\
\hline Geofísico & Terremotos & 0.59 & & 0.8 \\
& Erupções vulcânicas & 0.17 & & \\
Climático & Enchentes & & 8.6 & 18 \\
& Tempestades & Ciclone, tufão, furacão & 6.9 & 7.5 \\
& & Outras tempestades & 0.6 & \\
& Secas & 1.3 & 1.87 & \\
& Incêndios & 0.52 & & \\
Total & Deslizamentos & Temperaturas extremas & 0.005 & & \\
\hline
\end{tabular}

Fonte: Elaborado pelo autor a partir do IDCM, 2018: 7.

A Tabela 2 mostra que a maioria das pessoas deslocadas por "desastres" registrada em 2017, cerca de 96 por cento do total de 18,8 milhões de deslocados internos, foram afetados por eventos "relacionados ao clima", entre os quais a maioria correspondeu a enchentes (46 por cento) e tempestades, incluindo ciclones, furacões e tufões (40 por cento). O relatório destaca o fato de que as Américas foram responsáveis por 24 por cento dos deslocados internos relacionados a desastres registrados globalmente, e que na região o número de pessoas deslocadas por desastres foi 10 vezes maior do que aquelas que foram deslocadas por "conflito e violência" (IDCM 2018: 38). No entanto, as evidências do terreno nos levam a questionar até que ponto as violências ocorridas permanecem ocultas quando atribuímos o rótulo de "desastres" a esses eventos. Além disso, a significância estatística não deve nos levar a descartar a importância de eventos diretamente relacionados com conflito e violência. Por exemplo, outro relatório com foco em conflitos ambientais na América Latina registrado em 2017 concluiu que a região "continua no topo da escala de assassinatos globais de defensores da terra e do meio ambiente", acrescentando que "o agronegócio ultrapassou a mineração como a indústria mais ligada ao assassinato de ativistas - juntas, essas indústrias representam mais de $60 \%$ dos links conhecidos"(FGLOBAL WITNESS, 2018). O relatório também abordou a situação de Honduras, um país que infelizmente foi apontado como o caso exemplar de violência extrema contra os "defensores ambientais" em todo o mundo, embora os números de deslocados internos registrados em Honduras não sejam altos. O relatório da Global Witness fornece um quadro contundente dos complexos interesses transnacionais por trás da tortura e assassinato de pessoas locais que se opõem às atividades extrativistas em seus territórios:

Nossa investigação lança luz sobre os negócios secretos, subornos e transgressões da lei usados para impor projetos [de infra- 
estrutura] e silenciar a oposição. Também examinamos como os EUA estão financiando as forças do Estado hondurenho, que estão por trás de alguns dos piores ataques. [...] Documentamos inúmeros ataques e ameaças assustadoras, incluindo espancamento selvagem de mulheres grávidas por soldados, crianças sob a mira de armas da polícia, ataques incendiários em casas de moradores, enquanto assassinos contratados ainda vagam livremente entre as comunidades de suas vítimas [...] os EUA [...] contribuíram com US \$ 100 milhões em ajuda bilateral [...]. Mas dezenas de milhões de dólares de ajuda foram direcionados à polícia e aos militares, ambos os quais estão fortemente implicados na violência contra ativistas agrários e ambientais. [...] A embaixada dos EUA tem promovido o aumento do investimento nas indústrias extrativas de Honduras, por exemplo, com a gigante da mineração americana Electrum já planejando um investimento de US \$ 1 bilhão"(GLOBAL WITNESS, 2017; LAKHANI, 2017; LAKHANI, 2018).

O envolvimento de governos e atores locais e transnacionais em diferentes formas de violência extrema contra comunidades indefesas que lutam para defender seus territórios e meios de subsistência também foi registrado em muitos outros países da região, notadamente no Brasil (VALENCIO, 2010; ZHOURI, LASCHEFSKI, 2010; VALENCIO, 2012; CPT, 2019), Colômbia (VÉLEZ GALEANO, 2017) e México (POMA, 2017; KLOSTER, 2018), mas também nas Américas e em outros continentes (BLACK, 2001; PELUSO; WATTS, 2001; SRIDHAR , 2006; DOWNEY; BONDS, 2010; NIXON, 2011; BETTINI, 2013; WOMIN, 2014; ZIMMERER, 2014; JUSTIÇA AMBIENTAL, 2019; LYONS, 2019). A este respeito, embora seja óbvio para os especialistas, é preciso dizer que a referência à violência e aos desastres incluída nos parágrafos anteriores como ilustração dos principais argumentos não pode pretender fornecer nem mesmo uma síntese das evidências empíricas disponíveis para fundamentar o "conceito ampliado de violência", conforme discutido anteriormente e representado no Quadro 1. Voltarei a isso mais tarde.

\section{Naturalizando “desastres" e antropomorfizando a Natureza}

Tem havido um debate de longa data e ainda em curso entre os cientistas sociais sobre a importância relativa dos fatores sociais na explicação dos processos ambientais, com contribuições de uma ampla gama de tradições teóricas, segundo as quais o caráter entrelaçado dos processos sociais e "naturais" tem sido bem estabelecido. Não obstante, pode-se argumentar que, no mundo mais amplo, fora de nossas discussões especializadas, além da supervisão potencial do fato de que os desastres estão quase universalmente ligados à violência e ao conflito de maneiras diferentes, há uma tendência de 
"naturalizar" os desastres de forma a esconder o papel dos humanos em sua produção e seus impactos ou de negar totalmente a responsabilidade humana. Por outro lado, há também uma tendência a antropomorfizar a natureza e os processos naturais, o que muitas vezes também contribui para ocultar ou negar a dimensão social dos desastres e suas consequências. Além disso, a "naturalização" dos desastres e a antropomorfização da Natureza também contribuem para a invisibilização das desigualdades sociais estruturais que estão na origem dos impactos enormemente desiguais das violências socioecológicas. Para ser justo, no caso do relatório do IDCM sobre deslocamentos populacionais, qualquer tentativa de analisar a ocorrência e os enormes impactos de desastres como sendo principalmente o resultado de causas "naturais", geofísicas ou relacionadas ao clima é dissipada desde o início no relatório em si, que afirma:

Fatores de risco complexos e interdependentes, incluindo pobreza e desigualdade, instabilidade política e fragilidade do estado, estresse hídrico e insegurança alimentar, mudança climática e degradação ambiental, desenvolvimento insustentável e planejamento urbano pobre combinam-se de maneiras diferentes em países diferentes para aumentar a exposição das pessoas e vulnerabilidade ao deslocamento (IDCM, 2018, p. 2)

Esse reconhecimento de como eventos relacionados ao meio ambiente estão entrelaçados com fatores socioeconômicos e políticos deve ser bem-vindo. Apesar do conhecimento acumulado e das crescentes evidências empíricas sobre a interconexão espacial e temporal dos processos socioecológicos, há uma tendência persistente de "naturalizar" os desastres, incluindo a negação militante de responsabilidade sobre suas causas e consequências, por governos, empresas multinacionais, e outros atores poderosos. Um exemplo recente disso foi a cobertura da mídia sobre o "maior desastre ambiental" do Brasil, nas palavras da ex-presidente Dilma Rousseff, causado pelo rompimento de uma barragem de rejeito do complexo mineiro Samarco em Mariana, estado de Minas Gerais, Brasil, em 5 de novembro de 2015. O desastre foi enorme, teve consequências de longo alcance e longo prazo que ainda não foram totalmente compreendidas e, mais importante, as comunidades humanas afetadas ainda estão esperando por uma compensação adequada e soluções para suas necessidades urgentes. Ficou claramente estabelecido que os proprietários multinacionais da Samarco são responsáveis pelo acidente que causou o desastre e que a falta de regulamentação adequada contribuiu para isso (LOSEKANN, OLIVEIRA SÁ et al., 2015; HATJE, PEDREIRA et al., 2017; TUNCAK, 2017). Mesmo assim, a grande mídia nacional divulgou amplamente o evento como "o maior desastre natural do Brasil" (AZEVEDO, $2016^{*}$ grifo meu). A discussão continua exacerbada pela recente ocorrência de um desastre muito semelhante envolvendo algumas das mesmas empresas multinacionais, ocorrido em Brumadinho, também em Minas Gerais, Brasil, em 28 de fevereiro de 2019 (DARLINGTON, GLANZ et al., 2019). A “naturalização” dos desastres está tão 
profundamente enraizada que mesmo instituições como as Nações Unidas têm dificuldade em adotar uma terminologia mais avançada, como sugerido por relatórios como: "uma em cada três crianças perde a escola em países afetados por conflitos ou desastres naturais [19 Setembro de 2018] "ou“ um novo relatório das Nações Unidas alerta sobre a ligação entre as mudanças climáticas e o aumento da recorrência de desastres naturais [10 de outubro de 2018] "(UM, 2019 - grifo meu). Infelizmente, esses exemplos de conceitualização essencialista e reducionista de eventos socioecológicos complexos, como desastres, não são isolados, mas sim parte de um padrão global bem documentado, que não podemos abordar adequadamente neste artigo.

A naturalização de desastres tem o efeito de limitar, senão negar totalmente, a importância das ações e responsabilidades humanas na ocorrência e nos impactos dos desastres. No entanto, como afirmado no início dos anos 1970 por cientistas que trabalhavam com a teoria da complexidade e a sociogênese dos desastres "naturais", "a natureza se declara inocente” (GARCÍA, SMAGORINSKY, 1981). Por outro ângulo, além de "naturalizar" os desastres, esconder a mão do homem na sua feitura muitas vezes é feito antropomorfizando a Natureza. Há um tratamento persistente dos desastres como formas "naturais" de violência, a "violência da Natureza", que se tornou um antropomorfismo atual e conveniente. Por exemplo, em um artigo que lista uma série de eventos ambientais extremos registrados em todo o mundo em 2017, um repórter afirmou que "[n] desastres naturais estabeleceram recordes em todo o mundo em 2017 [...] olhe para alguns dos poderes mortais que a Mãe Natureza exerceu em 2017" (BRUECK, $2017^{\star}$ minha ênfase). Em outro exemplo, o Museu Americano de História Natural postou um vídeo educacional intitulado "Fúria da Natureza: A Ciência dos Desastres Naturais", e explicou que "terremotos, vulcões, tornados, furacões [...] são eventos naturais [que] nos lembram que nós são pequenos e vulneráveis - e que viver neste planeta dinâmico sempre acarretará riscos"(AMERICAN MUUSEUM OF NATURAL HISTORY, 2014, meu grifo). Abordagens mais pragmáticas também aproveitam o antropomorfismo, como ilustrado por um anúncio de venda de apólices de seguro, que exortava os leitores a "Agir agora, antes que haja um ato de Deus", referindo-se ao que as seguradoras descrevem como "grandes catástrofes", "atos da natureza" causados por uma "força superior", como raios, incêndios, vendavais, erupções vulcânicas, inundações, etc. (CAVAGLIERI, 2014, grifo meu). A “fúria da natureza” há muito se tornou um alvo adequado para a mercantilização, um processo marcado pela produção e reprodução de formas materiais, epistêmicas e culturais de violência.

\section{Conclusão: violências socioecológicas, resistências e ordens}

Durante as últimas décadas, tem havido um acordo crescente sobre a centralidade dos fatores antrópicos entre as causas das transformações ambientais em grande escala. Isso agora inclui uma campanha contínua coordenada por cientistas para o reconhecimento oficial da existência de uma "unidade geológica" definida dentro da "Escala de Tempo Geológico" denominada Antropoceno, que teria começado no 
início do século XIX por volta do início da Revolução Industrial na Europa, conforme proposto originalmente pelo vencedor do Prêmio Nobel Paul Crutzen (STEFFEN, SANDERSON et al. 2004; ANTHROPOCENE WORKING GROUP, 2019). Há um debate importante entre geólogos e outros sobre a força científica da proposta, mas também sobre a adequação do termo, visto que cientistas sociais estão cansados do reducionismo potencialmente apolítico que estaria implícito no termo "Antropoceno" propondo alternativas como "Capitaloceno" (ANTHROPOCENE WORKING GROUP, 2019). Esse ambicioso debate destaca a interconexão entre escalas de tempo geológicas e humanas, e o ritmo e escala diversificados de mudança e transformação que as caracterizam. A complexidade desconcertante de tais problemas não deve tirar o foco das tarefas essenciais necessárias para melhorar nossa compreensão da "rede vital de interdependências em que as vidas humanas evoluem", incluindo o desenvolvimento e transformação de regimes e ordens socioecológicas (DE VRIES, GOUDSBLOM, 2002, p. 414).

Nesse sentido, o estudo das violências socioecológicas, em suas diferentes manifestações, pode contribuir para uma melhor compreensão do surgimento, consolidação, expansão e destruição das ordens sociais. O reconhecimento de que processos de transformação social de muito longo prazo resultam do entrelaçamento amplamente cego, não planejado e descontrolado de eventos socionaturais não nos priva necessariamente de discernir a direção geral desses processos. Portanto, pode-se argumentar que na manifestação que Goudsblom chamou de "paradoxo da pacificação" (GOUDSBLOM, 2001) são as contradições internas de uma ordem mundial capitalista discursivamente comprometida com a busca da liberdade, paz e democracia, mas na prática implacavelmente orientada para a monopolização do poder econômico e da riqueza privada, muitas vezes por meio de extrema violência, e resultante escalada sem precedentes de desigualdades estruturais e injustiça. Como Galtung colocou há muito tempo, "eu vejo a violência como insultos evitáveis às necessidades humanas básicas e, mais geralmente, à vida, reduzindo o nível real de satisfação das necessidades abaixo do que é potencialmente possível” (GALTUNG, 1990, p. 292). Esses insultos evitáveis parecem atingir níveis cada vez mais elevados quando as lutas de resistência contra o avanço de formas renovadas de acumulação criminosa primitiva organizada e promovida por Estados nacionais e empresas multinacionais, apoiadas tacitamente, senão abertamente por instituições internacionais criadas para promover a paz e o desenvolvimento duradouros, são criminalizados como atividades terroristas e negados o status de legítima defesa. Isso pode ser ilustrado, infelizmente, com a situação das comunidades camponesas, indígenas e afrodescendentes no Brasil, que têm sido alvo de massacres recorrentes devido à resistência à expansão das atividades extrativistas que levam à apropriação ilegal de seus territórios. Como afirma a Comissão Pastoral da Terra que apoia o movimento dos trabalhadores sem-terra no Brasil, "lutar não é crime, não vamos esquecer [os massacres]" (CPT, 2019). E ainda, em outubro de 2018, milhões de brasileiros votaram em um presidente que fez campanha pela criminalização daqueles que defendem seu direito a terra e a um ambiente seguro de forma mais 
geral, sob acusações de terrorismo, levando a imprensa crítica a denunciar que o novo presidente "promove a carnificina rural e o holocausto ecológico", para não dizer o fim de uma democracia já frágil e incipiente (BALLOUSSIER, 2018; CARTA CAPITAL, 2018). Seria totalmente errado considerar o exemplo brasileiro como um caso isolado no quadro do progresso democrático. Ao contrário, deveria ser examinado como um experimento piloto, junto com os processos de desmantelamento rápido das estruturas democráticas básicas e frágeis e processos em curso na maioria países da região da América Latina e Caribe. Conforme relatado pela Comissão Econômica das Nações Unidas para a América Latina e o Caribe (ECLAC), a América Latina teve um desempenho melhor do que os países da Organização para Cooperação e Desenvolvimento Econômico (OCDE) em resposta à crise financeira de 2008 e fez avanços significativos na redução pobreza extrema e outros aspectos relevantes para nossa discussão, mas houve uma reversão rápida desde 2015 (ECLAC, 2016, p. 47-56; ECLAC, 2017, p. 2430). O retorno do extremismo de mercado neoliberal que, em certos casos como o do Brasil, se casa com projetos políticos neofascistas explícitos, lança sérias dúvidas sobre as possibilidades de avançar em processos de democratização substantiva em um futuro previsível. Essa reversão bárbara dos padrões morais e compromissos com o bem-estar civilizado universal, emprestada de Hobsbawm (1994), é uma expressão de um momento no processo de longo prazo de desenvolvimento e emergência de uma ordem ou ordens socioecológicas potencialmente novas, que provavelmente não devemos nos apressar em nomear, ainda não.

Uma tarefa fundamental na produção de conhecimento sobre violência e ordens socioecológicas está na primazia da formulação de questões e problemas de conhecimento sobre respostas e prescrições antecipadas. O conhecimento científico é a resposta aos problemas do conhecimento, formulados como questões de pesquisa. Em relação à violência e ordens socioecológicas, quais problemas de pesquisa têm prioridade? Que perguntas estão sendo formuladas? Que perguntas devem ser formuladas? Por que essas perguntas e nenhuma outra? Quem está formulando as perguntas? De quem são os interesses abordados nessas questões? Que violência? Violência de quem? Os reducionismos e determinismos prevalecentes, especialmente os tecnocêntricos, mas também os socialismos, continuam sendo os principais obstáculos em nossa busca pelo avanço do conhecimento que possa contribuir para transformações progressivas nessa área. Como já estabelecido na literatura, o domínio de entendimentos reducionistas e deterministas dos processos de "desenvolvimento" e de sua inter-relação com, digamos, processos de democratização e mercantilização, inclusive entre cientistas sociais progressistas e atores políticos, continua a ser um desafio formidável em nossa busca por compreensões e explicações mais avançadas e complexas de ordens e distúrbios socioecológicos. Esse tipo de conhecimento é essencial para contestar e derrotar a lamentável, mas exitosa, erosão neoliberal e neofascista de princípios, valores e práticas necessários à construção de ordens socioecológicas mais humanas e universalistas, alicerçadas na defesa do bem comum, como bem público, liberdade emancipatória, igualdade, inclusão e direitos humanos. 


\section{Referências}

ACI - Agencia Católica de Informaciones . "Obispos de Paraguay condenan asesinato de indígena frente a Congreso Nacional.” ACI Prensa. Asuncion: ACI, 2019. Disponível em: https://www.aciprensa.com/noticias/obispos-de-paraguay-condenan-asesinato-de-indigena-frente-a-congreso-nacional-78888. Acesso em março de 2019.

ANDREWS, A. "The right to breathe clean air", United Nations Environment Programme (UNEP), 2017. Disponivel em: https://www.unenvironment.org/news-and-stories/story/right-breathe-clean-air. Acesso em fevereiro de 2019.

ANTHROPOCENE WORKING GROUP. "What is the 'Anthropocene'? - Current Definition and Status, 2019. Disponível em: http://quaternary.stratigraphy.org/ working-groups/anthropocene/. Acesso em março de 2019.

ARECO, A. \& M. PALAU. Judicialización y violencia contra la lucha campesina. Casos de criminalización en el período 2013-2015. Asuncion: Base Investigaciones Sociales, 2016

AZEVEDO, A. L. “Desastre de Mariana ainda esta vivo.” O Globo, 6 November 2016. Disponível em: https://oglobo.globo.com/brasil/desastre-de-mariana-ainda-esta-vivo-20416385. Acesso em Fevereiro de 2019.

BALLOUSSIER, A. V. “Movimentos temem que até 'like’ baste para virarem terroristas no governo Bolsonaro.” Folha de Sao Paulo. 6 December 2018. Disponível em: https://www1.folha.uol.com.br/poder/2018/12/movimentos-temem-que-ate-like-baste-para-virarem-terroristas-no-governo-bolsonaro.shtml. Acesso em Fevereiro de 2019.

BETTINI, G. "Climate Barbarians at the Gate? A critique of apocalyptic narratives on 'climate refugees"' Geoforum 26(1): 63-72, 2013.

BLACK, R. "Environmental refugees: myth or reality?", Working Papers, New Issues in Refugee Research. Brighton, University of Sussex, 2001.

BRUECK, H. "Natural disasters set records around the world in 2017 - these were the worst."2017. Disponível em: https://www.businessinsider.com/worst-natural-disasters-hurricane-flood-wildfire-2017-12. Acesso em março de 2019.

CAPONERA, D. A. Water Laws in Moslem Countries. Rome: Food and Agriculture Organization (FAO), 1954. 
CARTA CAPITAL. "Bolsonaro insufla carnificina no campo e holocausto ecológico". Carta Capital. 13 October 2018. Disponível em: https://www.cartacapital.com.br/ politica/bolsonaro-insufla-carnificina-no-campo-e-holocausto-ecologico. Acesso em março de 2019.

CAVAGLIERI, C. "Act now, before there's an act of God." The Independent. 8 February 2014. Disponível em: https://www.independent.co.uk/money/insurance/act-now-before-theres-an-act-of-god-9116945.html. Acesso em março de 2019.

CIVIC, M. A. "A comparative analysis of the Israeli and Arab water law traditions and insights for modern water sharing agreement ", Denver Journal of International Law and Policy 26(3): 437-452, 1988.

CLAUSEWITZ, C. von (1989). On War. Princeton: Princeton University Press, 1989.

CPT - Pastoral Land Commission. "Massacres no campo.” 2019. Disponível em: https://www.cptnacional.org.br/mnc/. Acesso em março de 2019.

CROSSETTE, B. "Severe water crisis ahead for poorest nations in next 2 decades." The New York Times, 1995. Disponível em: https://www.nytimes.com/1995/08/10/ world/severe-water-crisis-ahead-for-poorest-nations-in-next-2-decades.html. Acesso em março de 2019.

DABÈNE, O. "La cuarta ola de regionalismo", en E. Jourcin (Ed.), Los Desafíos del Desarrollo en América Latina. Dinámicas Socioeconómicas y Políticas Públicas. Paris: Agence Française de Développement (AFD): 64-95, 2014.

DARLINGTON, S., J. GLANZ, M. ANDREONI, M. BLOCH, S. PEÇANHA, A. SINGHVI, and T. GRIGGS. "A tidal wave of mud." The New York Times. 29 February 2019. Disponível em: https://www.nytimes.com/interactive/2019/02/09/world/americas/brazil-dam-collapse.html. Acesso em março de 2019.

DAVIES, T. “Toxic space and time: slow violence, necropolitics, and petrochemical pollution." the American Association of Geographers, Annals...108(6): 1537-1553, 2018.

DE PAULA, G. "Diseño de políticas de defensa para el control y defensa de recursos naturales estratégicos.” Revista Política y Estrategia. (114): 243-270, 2009.

DESDEMO. La desigualdad y la injusticia socio-ecológicas como obstáculo al proceso de democratización en América Latina y el Caribe. Un estudio teórico y empírico (DESDEMO). 2019. Disponível em: www.desdemo.org. Acesso em dezembro de 2021. 
DE VRIES, B. and J. Goudsblom. Mappae Mundi. Humans and their Habitats in a Long-Term Socio-Ecological Perspective. Myths, Maps, and Models. Amsterdam: Amsterdam University Press, 2002.

DOWNEY, L., E. Bonds, and K. "Natural resource extraction, armed violence, and environmental degradation.” Organization \& Environment 23(4): 417 -445, 2010.

ECLAC - United Nations Economic Commission for Latin America and the Caribbean (2016). Horizons 2030: Equality at the centre of sustainable development. Santiago de Chile: ECLAC, 2016.

ECLAC - United Nations Economic Comission for Latin America and the Caribbean. Annual report on regional progress and challenges in relation to the 2030 Agenda for Sustainable Development in Latin America and the Caribbean. Santiago de Chile: ECLAC, 2017.

ELIAS, N. The Civilizing Process. The History of Manners, and State Formation and Civilization. Oxford, United Kingdom and Cambridge, Massachusetts, USA: Basil Blackwell, 1994.

FAO - Food and Agriculture Organization. “The Right to Food." 2019. Disponível em: http://www.fao.org/right-to-food/en/. Acesso em março de 2019.

FERNANDEZ EVANGELISTA, G. C. \& JONES, S. E. "Mean Streets. A Report on the Criminalisation of Homelessness in Europe”. Brussels: Fédération Européenne d'Associations Nationales Travaillant avec les Sans-Abris (FEANTSA), 2013.

FLETCHER, J. Violence \& Civilization. An Introduction to the Work of Norbert Elias. Cambridge: Polity Press, 1997.

GALTUNG, J. “Violence, peace, and peace research.” Journal of Peace Research 6(3): 167-191, 1969.

GALTUNG, J. “Cultural Violence.” Journal of Peace Research 27(3): 291-305, 1990.

GARCÍA, R. \& SMAGORINSKY J. Nature Pleads Not Guilty, Pergamon Press, 1981.

GLEICK, P. "Water and conflict: fresh water resources and international security." International Security 18(1): 79-112, 1993. 
GLOBAL WITNESS. "Honduras. The deadliest place to defend the planet”. 2017. Disponível em: https://www.globalwitness.org/documents/18798/Defenders_Hondu ras_full_report_single_v5_AH12dtf.pdf. Acesso em março de 2019.

GLOBAL WITNESS. "New data reveals 197 land and environmental defenders murdered in 2017.” 2018. Disponível em: https://www.globalwitness.org/en-gb/blog/new-data-reveals-197-land-and-environmental-defenders-murdered-2017/. Acesso em março de 2019.

GOUDSBLOM, J. "The theory of the Civilising Process and its discontents". Amsterdam: Amsterdam School for Social Research, 1994.

GOUDSBLOM, J. “The Paradox of Pacification”. Amsterdam: Norbert Elias Foundation, 2001.

HALL, S. D. "War by other means: environmental violence in the 21st Century". Doctoral Thesis, Environmental Studies Program. Eugene, OR, University of Oregon, 2017.

HATJE, V. at al. "The environmental impacts of one of the largest tailing dam failures worldwide." Scientific Reports(10706): 1-13, 2017

HIRSCH, A. M. (1959). "Water legislation in the Middle East." American Journal of Comparative Law 8: 168-186, 1959.

HOBSBAWM, E. “Barbarism: A User’s Guide.” New Left Review I(206): 44-54, 1994.

HSIANG, S. M. at al. "Quantifying the Influence of Climate on Human Conflict." Science 341(1235367), 2013.

IDCM - Internal Displacement Monitoring Centre. Global Report on Internal Displacement 2018. Geneva: IDCM, 2018.

JOAS, H. \& KNÖBL, W. War in Social Thought: Hobbes to the Present. Princeton and Woodstock, UK: Princeton University Press, 2013.

KLOSTER, K., Ed. Water conflicts, violence, and capitalist territorialisation in Latin America, WATERLAT-GOBACIT Network Working Papers, 4(4), 2018. Disponível em: http: //waterlat.org/publications/working-papers-series/vol4/vol4no4/. Acesso em março de 2019.

KULETZ, V. “Invisible spaces, violent places: Cold War nuclear and militarized landscapes”, in N. L. Peluso and M. Watts (Eds.). Violent Environments. Ithaca, NY: Cornell University Press: 237-260, 2001. 
LAKHANI, N. "Honduras elites blamed for violence against environmental activists." The Guardian. 31 January 2017. Disponível em: https://www.theguardian.com/ world/2017/jan/31/honduras-environmental-activists-global-witness-violence-berta-caceres. Acesso em março de 2019.

LAKHANI, N. Berta Cáceres murder trial plagued by allegations of cover-ups set to end. The Guardian. 29 November 2018. Disponível em: https://www.theguardian. com/global-development/2018/nov/29/berta-caceres-trial-plagued-by-allegations-of-cover-ups-set-to-end. Acesso em março de 2019.

LANDINI, T. S. and F. DEPELTEAU, Eds. Norbert Elias and Violence. New York: Palgrave Macmillan, 2017.

LINKLATER, A. \& MENNELL, S. "Norbert Elias, the civilizing process: sociogenetic and psychogenetic investigations-an overview and assessment." History and Theory 49(3): 384-411, 2010.

LOSEKANN, C. at al. "Sem-Terra, Sem-Água e Sem-Peixe - Impactos socioambientais da ruptura da barragem de rejeitos da Samarco no Espírito Santo." WATERLATGOBACIT Network Working Papers 2(17): 8-35, 2015. Disponível em: http://waterlat. org/WPapers/WPSATAD217.pdf. Acesso em março de 2019.

LYONS, K. "Securing territory for mining when Traditional Owners say 'No': The exceptional case of Wangan and Jagalingou in Australia." The Extractive Industries and Society. (No prelo). Disponível em: https://doi.org/10.1016/j.exis.2018.11.007. Acesso em março de 2019.

MATTHEW, R., HALlE M., \& SWITZER, J. Eds. Conserving the Peace: Resources, Livelihoods and Security. Winnipeg, Manitoba: International Institute for Sustainable Development and IUCN - The World Conservation Union, 2002.

MENNELL, S. Norbert Elias. An Introduction. Oxford and Cambridge, MA.: Blackwell, 1992.

MERCHANT, C. “The Scientific Revolution and the death of nature." Isis 97(3): 513-533, 2006.

MOHAI, P. “Environmental justice and the Flint water crisis.” Michigan Sociological Review 32: 1-41, 2018.

MOHAI, P. "Flint water crisis: Most egregious example of environmental injustice, says U-M researcher." 19 October 2018. Disponível em: https://news.umich.edu/flint-water-crisis-most-egregious-example-of-environmental-injustice-says-u-m-researcher/. Acesso em março de 2019. 
NATIONAL COALITION FOR THE HOMELESS. "Criminalization of homelessness." 2019. Disponível em: https://nationalhomeless.org/issues/civil-rights/. Acesso em março de 2019.

NIC - National Intelligence Council. Global Trends 2015: A Dialogue About the Future With Nongovernment Experts. Washington, DC.: NIC, 2000.

NIXON, R. Slow Violence and the Environmentalism of the Poor. Cambridge, Massachusetts, and London: Harvard University Press, 2011.

NOORGARD, R. B. Development Betrayed. The End of Progress and a Coevolutionary Revisioning of the Future. London: Routledge, 1994.

ORTEGA, G. Extractivismo en el Chaco Paraguayo. Un Estudio Exploratorio. Asuncion: Base Investigaciones Sociales, 2013.

PELUSO, N. L. \& WATTS, M., Eds. Violent Environments. Ithaca, NY: Cornell University Press, 2001.

PEPPERELL, N. “The unease with civilization: Norbert Elias and the violence of the civilizing process." Thesis Eleven 137(1): 3-21, 2016.

POMA, A. Defending Territory and Dignity. Emotions and Cultural Change in the Struggles against Dams in Spain and Mexico [in Spanish]. Campina Grande, Brazil, Seville, Spain, and Guadalajara, Mexico: WATERLAT-GOBACIT Network, State University of Paraiba Press (EDUEPB), School of Hispanic-American Studies (EEHA), Higher Council of Scientific Research (CSIC), and Western Institute of Technology and Higher Education (ITESO), 2017. Disponível em: http://waterlat.org/ publications/books/defending/. Acesso em março de 2019.

RUSSELL, B. \& MORRIS, N. “Armed forces are put on standby to tackle threat of wars over water." The Independent. 28 February 2006.

SCHWARTZ, D. \& SINGH A. Environmental Conditions, Resources, and Conflicts: An Introductory Overview and Data Collection. Nairobi: United Nations Environment Programme (UNEP), 1999.

SRIDHAR, V. "Why do farmers commit suicide? The case of Andhra Pradesh." Economic and Political Weekly 41(16): 1559-1565, 2006.

STEFFEN, W. at al. Global Change and the Earth System: A Planet Under Pressure. Berlin, Heidelberg, and New York: Springer-Verlag, 2004 
TUNCAK, B. "Lessons from the Samarco Disaster." Bussiness and Human Rights Journal 2(1): 157-162, 2017.

UN - United Nations. “Desastres Naturales.” 2019. Disponível em: https://news. un.org/es/tags/desastres-naturales. Acesso em março de 2019.

UNITED SATES OF AMERICA DEPARTAMENT OF THE NAVY. Navy Reestablishes U.S. 4th Fleet. Mayport, Fla.: United States of America Department of the Navy, 2008. Disponível em: https://www.navy.mil/submit/display.asp?story_id=36606. Acesso em março de 2019.

VALENCIO, N. "Desastres, ordem social e planejamento em defesa civil: o contexto brasileiro.” Saúde e Sociedade 19(4): 748-762, 2010.

VALENCIO, N., Ed. Sociologia dos Desastres. Construção, interfaces e perspectivas no Brasil. Sao Carlos, Sao Paulo, Brazil: RiMa Editora, 2012.

VÉLEZ GALEANO, H. "Gobernanza del agua en Territorios Ancestrales de Comunidades Negras en el Alto Cauca, Colombia." Doctoral Thesis, Doctorado Interinstitucional en Ciencias Ambientales. Santiago de Cali, Colombia: Universidad del Valle (UNIVALLE), 2017.

WEBER, M. Economy and Society. Berkeley, Los Angeles, and London: University of California Press, 1978.

WOMIN - African Women Unite Against Destructive Resource Extraction (2014). Women, Gender and Extractivism in Africa. A Collection of Papers. Johannesbourg, International Alliance on Natural Resources in Africa (IANRA), 2014. Disponível em: https://womin.org.za/images/papers/Full-collection-Women-gender-and-extractivismin-Africa.pdf. Acesso em março de 2019.

ZHOURI, A. \& LASCHEFSKI K., Eds. Desenvolvimento e Conflitos Ambientais. Belo Horizonte: Editora UFMG, 2010.

ZIMMERER, J. "Climate change, environmental violence and genocide" The International Journal of Human Rights 18(3): 265-280, 2014. 